1st International Conference - Global Ethics - Key of Sustainability (GEKoS) | May 15th, 2020 | Bucharest, Romania

\title{
Transparency Around the World. Empirical Study on Information Reported on Finanacial Markets
}

\author{
Irina Diana IORDACHE
}

https://doi.org/10.18662/lumproc/gekos2020/16

How to cite: Iordache, I.D. (2020). Transparency Around the World. Empirical Study on Information Reported on Finanacial Markets. In A. Grigorescu \& V. Radu (vol. ed.), Lumen Proceedings: Vol. 11. 1st International Conference Global Ethics - Key of Sustainability (GEKoS) (pp. 150-161). Iasi, Romania: LUMEN Publishing House.

https://doi.org/10.18662/lumproc/gekos2020/16 


\title{
Transparency Around the World. Empirical Study on Information Reported on Finanacial Markets
}

\author{
Irina Diana IORDACHE ${ }^{1 *}$
}

\begin{abstract}
The study analyzes the issue of transparency of the information reported by entities listed on various financial markets around the world.

The research consisted in the analysis of the annual reports of 120 companies listed on 8 stock exchanges. In constructing the sample, we've started from the bypothesis according to which the degree of transparency of the information presented by companies is directly proportional to the share they occupy in the structure of stock market indices. Finally, 10 stock market indices were analyzed.

It was concluded that in order to meet the requirements of transparency and regular reporting, listed entities need to adapt their organization and communication according to good governance practices and accounting rules, so that they are always engaged in an open dialogue with the market.

Analyzing the issue of economic-financial communication has led to the identification of extremely generous future research directions, among which we recommend: the study of the relationship between the transparency of economic-financial communication and the quality of corporate governance; studying the impact of decision-makers inestablishing the transparency of economic and financial communication;studying the relationship between the existence or non-existence of internal control mechanisms and the transparency of economic and financial communication, studying the impact of fraudulent financial-accounting reporting practices.
\end{abstract}

Keywords: IFRS; US GAAP; accounting; transparency; stock market; stock indices.

1 „1 Decembrie 1918" University from Alba Iulia, Romania.

(c) The Authors, LUMEN Conference Center \& LUMEN Proceedings.

Selection and peer-review under responsibility of the Organizing Committee of the conference

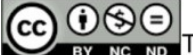

is an Open Access article distributed under the terms of the Creative Commons AttributionNoncommercial 4.0 Unported License, permitting all non-commercial use, distribution, and reproduction in any medium, provided the original work is properly cited 


\section{Introduction}

The current research paper is focusing broadly on the analysis of the financial communication in an economic framework characterized by permanent transformations and, in particular, on assessing and measuring the level of transparency of financial-accounting information.

The subject analyzed is topical and has been widely debated in the literature by many researchers, but there have been few papers that have dealt strictly with the issue of transparency of financial-accounting information. The conclusions they have reached are quite different, which motivates us to research this topic to bring new clarifications both conceptually and empirically.

In addition, the globalization of the markets generates an extremely competitive climate, which practically requires the presentation of the company through a well-created image in order to consolidate its own brand. Thus, in the context of increasing competitiveness, in order to conquer new markets, to increase the role and importance gained, all companies will be forced to meet the demands of the globalized market. In this sense, taking into consideration what has been found so far, our research refers to the role of financial-accounting information in economic-financial communication and we aim to identify the determinants that contribute to optimize this transparency.

How can the transparency of financial-accounting communication be evaluated and measured? This is the basic question we want to find answers to in our research.

\section{Problem Statement}

Over time, countries have developed their own accounting standards, based on rules, principles, business or tax guidelines.

Internationally, the regulatory frameworks most approved by investors are IFRS and US GAAP. Although the two systems each offer a set of principles, valuation rules, techniques for recording and reporting financial information, they are nevertheless based on different rationalities.

Thus, IFRSs are based on a general framework, established on a set of principles, definitions. Under this regulatory system, transparency is a qualitative requirement that an entity's management must meet when reporting financial statements [3]. In the case of US GAAP, in order to comply with this regulatory framework, the entities construct their accounting policies in such a way as to respond to an exhaustive list of rules and requirements. Such an approach has generated over time a cumbersome 
legislation of about 140,000 pages, but which manages to respond to most cases encountered in practice and very rare to give rise to interpretations [4].

Starting from this different approach in drafting the two regulatory frameworks, the question arises as to whether US accounting standards and IFRSs are similar and whether the information reported for the purpose of transparency requirements is comparable. In this respect, there is a continuing concern to ensure the convergence of the two sets of standards, an objective expressed by mutual agreement since 2002 by the Norwalk Agreement [5].

However, it is noted that there are still some differences between the two sets of regulations, especially as there are contradictory views between accounting specialists and there are loyal supporters of a single category of regulation. For example, David Tweedie in a 2012 statement argues that IFRS is a stronger set of regulations, as it is based on principles [1], while supporters of US GAAPs such as Braton and Cunningham believe that they are better because they provide clearer rules also based on principles, but which better manage revenue recognition [2].

In such debates the consensus is difficult to find as the measurement of differences is based on the technical approaches found in the two categories of accounting standards for the same kind of operations and activities.

\section{Research Questions/Aims of the research}

Regardless of the accounting standard applied, the question is: "What is the optimal level of transparency that a public entity must present to users?"

Starting from this objective and from the inherent risks appeared in the informational and the decisional process, through the performed study we aim to identify a stratification of the degree of informational transparency in which entities can fit.

In order to achieve the proposed objective, our study started from the following hypotheses:

H1. There is a positive correlation between the degree of transparency of the information presented by a listed entity and the share occupied at the level of stock market indices

H2. The international location of companies from a geographical point of view does not influence the quality of the information published in the annual reports 


\section{Research Methods}

The research hypotheses presented above were the starting point in our theoretical and empirical research. In this sense, during our investigation we sought to validate or not these hypotheses.

The study consisted in the analysis of the annual reports of 120 companies listed on 8major stock exchanges: New York, London Stock Exchange, Hong Kong Stock Exchange, Shanghai Stock Exchange, London, Hong Kong, Tokyo, Moscow, Switzerland and Bucharest. To define the sample of 120 companies, we've used the most representative stock market indices of those 8 stock exchanges. At the level of the New York Stock Exchange, we've used 3 indices, S \& P500, NASDAQ, Dow Jones. In the end, 10 stock market indices were analyzed and 12 companies were selected for each index as follows:

- the first 2 companies with the highest share in the index structure;

- the last 2 companies with the lowest share in the index structure; companies.

- 8 companies were randomly selected from the remaining

We decided to choose the stock market index as a selection criteria due to the fact that the most capitalized entities on the international financial markets are analyzed in the light of this indicator. Next, based on this argument, but also the need to obtain a comparable database, we gave for each entity grades from 1 to 12 , depending on its share in the structure of the index of which it is part of.

Further, in order to optimize the information that the entities report through the prism of transparency, we've built a scorecard consisting of 21 elements, representing categories of information necessary to determine the level of transparency.

In constructing the sample we started from the hypothesis that the degree of transparency of the information presented by a listed entity is directly proportional to the share occupied at the level of stock market indices. In the study we also tested this hypothesis.

\section{Findings}

A first result was the geographical identification of the application of the most representative accounting standards, namely IFRS and US GAAP. Thus, out of the 8 markets, we foundthe obligationto apply IFRS for listed domestic companiesonly amoung 3 stock markets (London Stock Exchange, Moscow Stock Exchange and Bucharest Stock Exchange), at the level of the Shanghai Stock Exchange, the Swiss Stock Exchange, the Stock Exchange from Hong Kong and the Tokyo Stock Exchange IFRS are recommended 
for listed companies, but not mandatory. Regarding the New York Stock Exchange, we found out that companies from the United States of America are managing their accounting by their own rules, US GAAP, these standards becoming the main competitor of IFRS. Also, from the analysis we conclude that among the listed companies that do not use IFRS, the vast majority (over 80\%) are companies listed in the United States, China, Japan and India.

Regarding the distribution around the world, according to Figure no. 1 , it can be seen how most jurisdictions that require or allow the use of IFRS among listed companies are found in Europe (44 states), followed by Africa with 36 countries.

Figure no. 1. Distribution of IFRS by continent in 2018

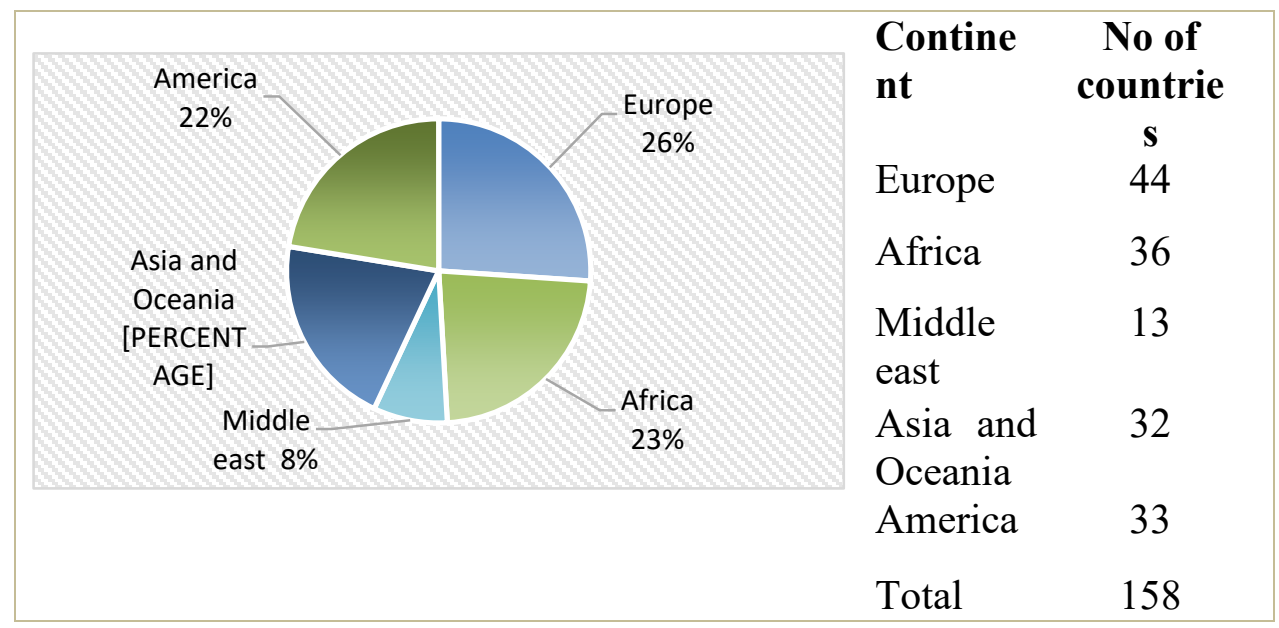

Source: Own processing based on ifrs.org data

Following the analysis of the 120 entities listed on the 8 capital markets, we identified a number of 21 elements that characterize the level of transparency of the information reported by each company.

We've grouped and summarized the information presented according to the theoretical objectives of transparency, finding that a number of 11 elements are found at the level of all companies studied. Thus, we concluded that the presentation of these 11 elements ensures a basic level of transparency regardless of the capital market where the entities operate. Compared to these elements, we also identified at the level of the studied reports another set of information, such as risk factors, management remuneration policy, etc. Their presentation, in addition to the 11 basic elements, we considered to extend the degree of transparency. In addition to 
the two categories of information, we also encountered a third set of information elements, such as information related to the production process or the presentation of anti-corruption policies, information rarely found in reports.

Therefore, we've evaluated the level of the communicated transparency through annual reports using the Grid for evaluating the information transparency in the annual reports, which we elaborated and based on which we assigned scores to the companies from the analyzed sample, according to the Table no. 1.

Tabel no 1. Grid for evaluating the transparency of financial-accounting information

\begin{tabular}{lccccc}
\hline $\begin{array}{l}\text { Informati } \\
\text { on level }\end{array}$ & $\begin{array}{c}\text { Inexistentinfo } \\
\text { rmation }\end{array}$ & Basic level & $\begin{array}{c}\text { Medium } \\
\text { level }\end{array}$ & High level & $\begin{array}{c}\text { Maximum } \\
\text { score }\end{array}$ \\
\hline $\begin{array}{l}\text { Score } \\
\text { range }\end{array}$ & 0 & $1-11$ & $12-15$ & $16-21$ & 21 \\
\hline
\end{tabular}

Source: Own processing

The calculation of the total score assigned to each company was done by summing the intermediate scores, according to the formula below:

\section{Total score $=$ Score basic level + Score medium level + Score high level}

This total transparency score was used as the dependent variable in testing our hypotheses.

Next, we tested and validated (or disproved) one by one our research hypotheses. In this sense, we used the univariate analysis, which allowed us to highlight the determinants that contribute to the transparency of the reported information. The synthesized resultsobtained after testing are presented in the Table no. 2.

Tabel no 2. Hypothesis testing

\begin{tabular}{clccc}
\hline Assumption & $\begin{array}{l}\text { Predictive } \\
\text { variables }\end{array}$ & $\begin{array}{c}\text { Expected } \\
\text { relationship }\end{array}$ & $\begin{array}{c}\text { Resulted } \\
\text { relationship }\end{array}$ & $\begin{array}{c}\text { Assumption } \\
\text { confirmation }\end{array}$ \\
\hline H1 & $\begin{array}{l}\text { Stock market } \\
\text { capitalization }\end{array}$ & + & + & H1 is valid \\
\hline
\end{tabular}


Irina Diana IORDACHE | Lumen Proceedings 11 | GEKoS2020

\begin{tabular}{lllll}
\hline H2 & $\begin{array}{l}\text { Geographical } \\
\text { area }\end{array}$ & - & + & $\mathrm{H} 2$ is rejected \\
\hline
\end{tabular}

Source: Own processing

In order to test our hypothesis, according to which companies with a higher share in stock indices (strong market capitalization) have the highest degree of transparency, we've measured the correlation of these variables using the Pearson coefficient in Eviews.

In this regard, for the comparability of the data, following the analysis of the 21 informational elements, we've assigned to each entity in our sample a score regarding the degree of transparency, between 11 and 21. We thus identify two significant elements in our research (Figure no. 2):

- The share of companies in stock market indices (X Axis)

- The score regarding the transparency level (Y axis)

Figure no. 2. The correlation between the information presented by the companies and their weight in the stock market indices

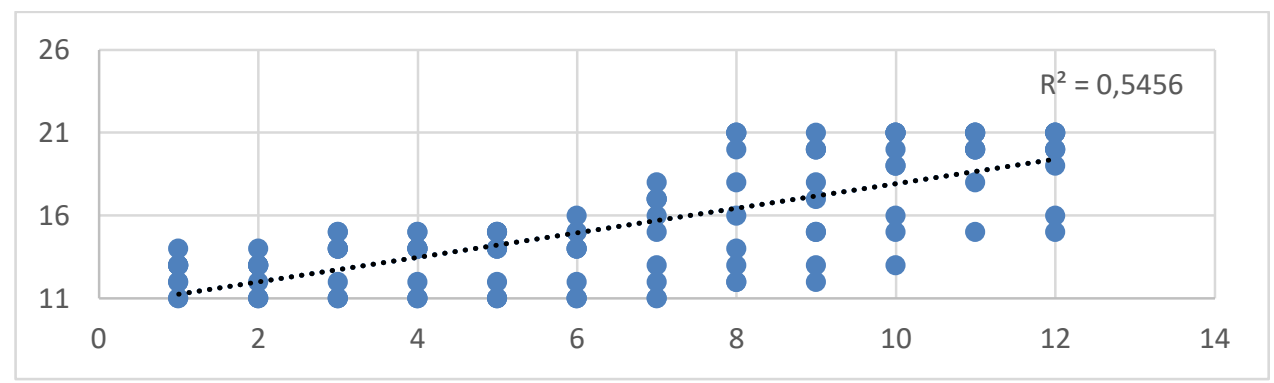

Source: Own projection based on Pearson correlation

In Figure no. 3 it is observed that there is a direct and positive correlation between the two elements. Also, the association of the two elements is relevant, concluding that there is a strong correlation between these two variables, because the Pearson correlation coefficient has the value of 0.73 . 
Figure no. 3. Interpretation of the value of the Pearson test

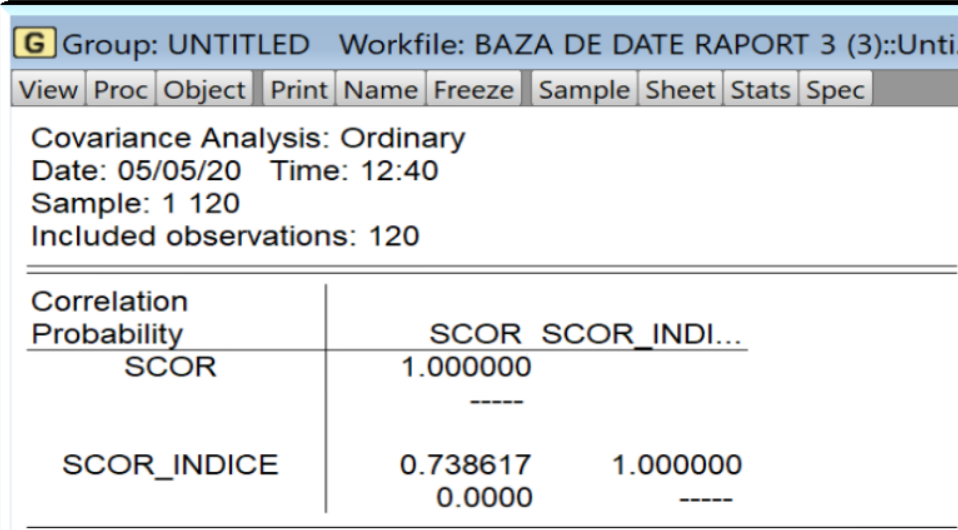

Source: Own processing in Eviews

Also, the correlation of the two variables is proved by thedetermination coefficient $r^{2}$. According to the theory, if $r^{2}$ is greater than 0.5 it means that the variables introduced in the matrix are strongly correlated and interdependent (Figure no. 4).

Figure no. 4. Formula and interpretation of the determination coefficient $r^{2}$

\begin{tabular}{ll}
\hline Formula & Interpretation based on Cohen (1988) \\
\hline & $\mathrm{r}^{2}=<0.30$ - there is no link \\
& $0.30<\mathrm{r}^{2}<0.50$ - there is an average link between \\
& the variables \\
& $\mathrm{r}^{2}=(\mathrm{rxy})^{2}$ \\
& each other
\end{tabular}

Source: Own processing based on Cohen, J. 1988. Statistical Power Analysis for the Behavioral Sciences, 2nd Edition

In our case $r^{2}$ being equal to 0.5456 , we can assume that $54 \%$ of the variation of the degree of transparency of the information presented by the studied entities is determined by the variation of the weights that these entities occupy within the stock market indices.

Therefore, our hypothesis is accepted and we conclude that an entity obtains a leading position on the capital market on which it operates if it is concerned with increasing the degree of transparency.

Furthermore, using this methodology, we've obtained a second result that highlights the global stratification of the level of transparency on the 8 
studied stock exchange. As seen in Figure no. 5 the companies with the highest concern in presenting a high degree of information are listed in New York Stock Exchange (Nasdaq - 13\%, Dow Jones - 12\%, S \& P500 - 10\%) and in London (FTSE100 - 10\%). A low level of transparency can be seen amoung companies listed on the stock markets in Asia, compared to those in Europe and America. Thus, we found out that from the information reported on Tokyo and Shanghai stock exchanges, only $2 \%$ of it is in the category of information with a high level of transparency. Most of the companies listed on these exchanges (approximately 90\%) have the minimum (basic) level of information that ensures transparency. At the level of Bucharest Stock Exchange, it is observed that $73 \%$ of the information presented ensures a basic level of transparency and, at the same time, the listed entities have the concern to increase the degree of transparency. However, few entities manage to provide information with a higher degree of transparency $(5 \%)$.

Figure no. 5. Degree of transparency on the 8 studied stock exchanges

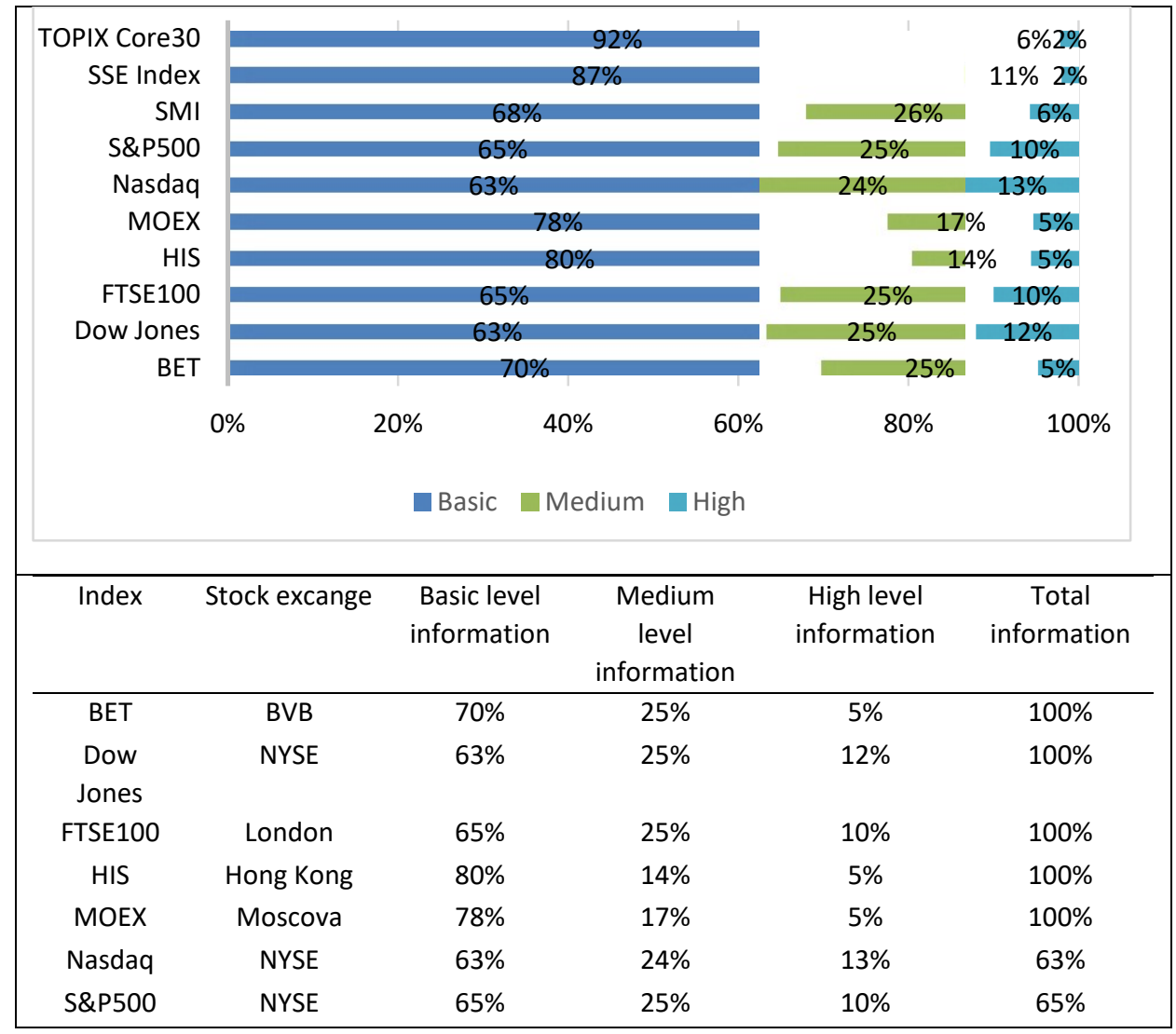


Irina Diana IORDACHE | Lumen Proceedings 11 | GEKoS2020

\begin{tabular}{|cccccc|}
\hline SMI & Switzerland & $68 \%$ & $26 \%$ & $6 \%$ & $68 \%$ \\
SSE Index & Shanghai & $87 \%$ & $11 \%$ & $2 \%$ & $87 \%$ \\
TOPIX & Tokyo & $92 \%$ & $6 \%$ & $2 \%$ & $92 \%$ \\
Core30 & & & & & \\
\hline
\end{tabular}

Source: Own projection

\section{Discussions}

Summarizing the research results and taking into account our goal of finding a solutions for presenting an optimal level of transparent information, we identified three categories of entities, depending on the level of information presented. Finally, we found out that in the managing process an important place is occupied by the concern of understanding the process of obtaining and presenting information through transparency, which is why an essential condition in improving the entity's performance is awareness of the differences between a selective and subjective presentation of information and a total transparency.

As we have tested and observed that the highest level of transparency currently means the presentation of the 21 elements, we consider that it is up to the companies to identify the categories of information to be presented in order to achive an optimal level of transparency.

As a result of the hierarchy of the elements identified by our study, schematically the construction of the strategies for optimizing the transparency can be achieved by evolving the levels of transparency presented in Figure no. 6. 
Figure no. 6.Selective transparency versus total transparency

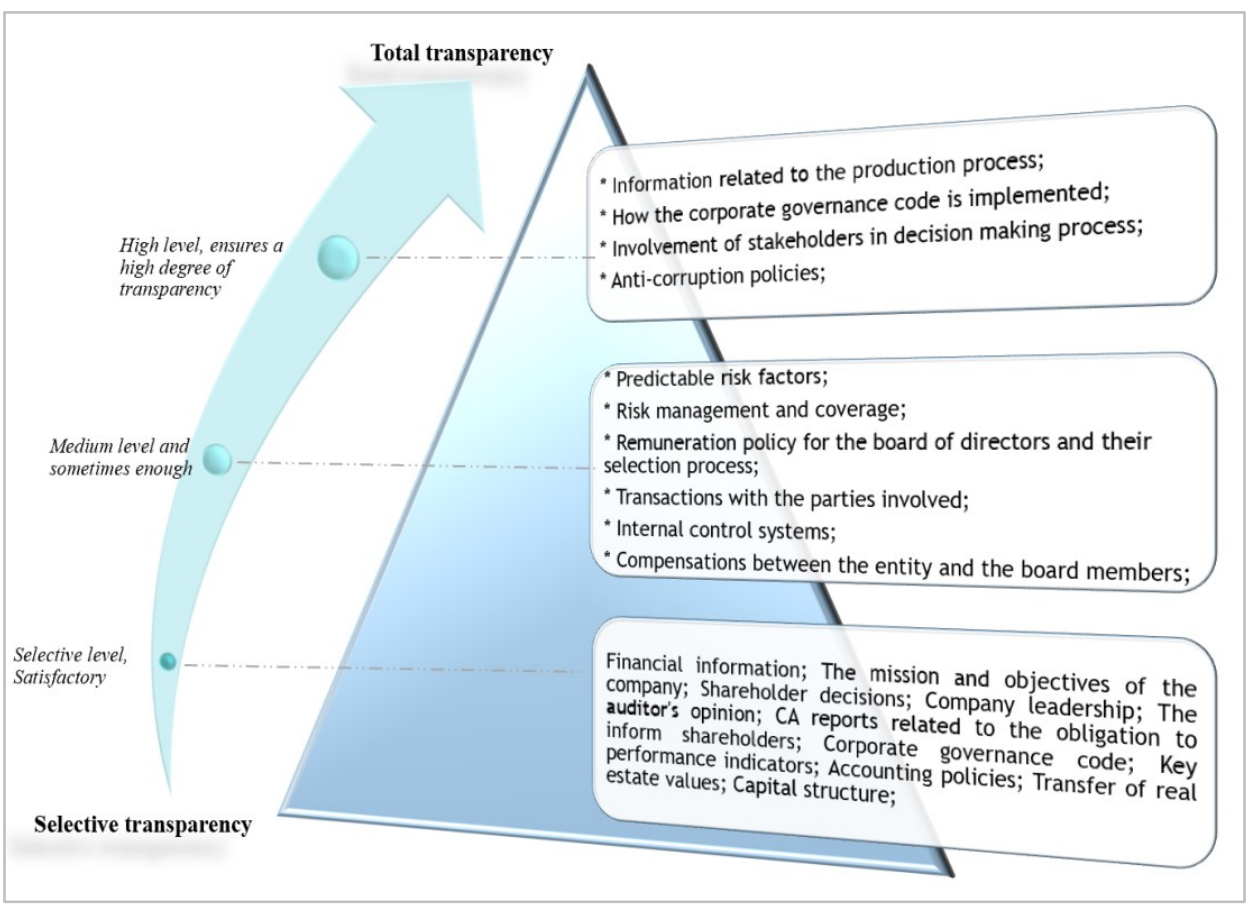

Source: Own projection

Thus, in order to meet the requirements of transparency and regular reporting, listed entities must adapt their organization and communication strategies according to good governance practices and accounting regulations, so that they are always engaged in an open dialogue with the market. The level of transparency also comes from the way in which the management of each entity knows how to take responsibility and build an optimal information system based on the cost-benefit ratio, through which to ensure that all shareholders and investors are treated equally.

\section{Conclusions}

As a result of this study, to the listed entities we recommendto have a proactiveattitude, and therefore the management to be aware of all instruments they have in building an optimal transparency strategy without fear of affecting its competitive position on the market, by presenting the so-called "sensitive" information.

As a final conclusion, based on the results of this study, we found out that entities listed on any of the 8 capital market studied are concernedin achieving a high level of transparency of the presented information and that 
this is an ongoing process both in terms of regulations and policies and of the managerial process. This conclusion is especially evident after we've tested the correlation between the level of transparency and the competitive success of each entity.

Moreover, we consider that the results of our research represent a useful information base and a starting point in evaluating and analyzing the transparency of financial-accounting communication, which can be extended and developed in other fields.

A possible limitation of this research could be the fact that only 8 financial markets have been studied. For future studies, an interesting perspective could be the exploration of financial markets with different particularities, such as the financial markets in China or those in Islamic countries.

\section{Acknowledgement}

This work is part of the project „Development of tertiary education in support of economic growth - PROGRESSIO", project codePOCU/380/6/13/125040, project co-financed by the European Social Fund through the Human Capital Operational Program 2014 - 2020.

\section{References}

[1] Street D. L. An Interview with Sir David Tweedie, Journal of International Financial Management \& Accounting. 2012; 13(1).

[2] Bratton, WW, Cunningham LA. "Treatment Differences and Political Realities in the GAAP-IFRS Debate", 2013, Faculty Scholarship. Paper 858.

[3] Ernst and Young. US GAAP versus IFRS The basics; February 2018. Available from: https://www.ev.com/Publication/vwLUAssets/IFRSBasics 00901181US 23 February2018/\$FILE/IFRSBasics 00901-181US 23February2018.pdf,

[4] KPMG. IFRS compared to US GAAP; 2017. Available from: https://assets.kpmg/content/dam/kpmg/xx/pdf/2017/12/ifrs-us-gaap2017.pdf

[5] Memorandum of Understanding "The Norwalk Agreement"; 2002. Available from: https://www.fasb.org/news/memorandum.pdf 